\title{
Effect of Bauschinger Effect Parameters on the Springback of High Strength Steel Stamping
}

\author{
Nidan Han*, Wenyu Ma, Xuebin Zheng and Jianwei Yang \\ Shougang Research Institute of Technology, Beijing, China \\ ${ }^{*}$ Corresponding author
}

\begin{abstract}
The springback phenomenon in sheet metal stamping will lead to problems in subsequent assembling, and cannot guarantee parts dimensional accuracy, it is necessary to research spring-back parts effect in part stamping molding. Due to the high strength steel has a high yield strength, the springback after unloading increases, advanced high strength steel plates show unique material properties in reverse loading, the Bauschinger effect, which makes it more difficult to predict springback accurately. In this paper, by finite element simulation of stamping process of DP steel $s$ shape beam in Autoform, the Bauschinger effect was taken into account. The effect of parameters of kinematic hardening model in Bauschinger effect on the springback after stamping molding was mainly discussed. The result shows that, with the increasing of transient softening rate $\kappa$, the maximum springback increases. The increasing of Stagnation Ratio $\zeta$ reduces the springback.
\end{abstract}

Keywords — bauschinger effect; springback; high strength steel

\section{INTRODUCTION}

Springback is one of the key factors to consider in sheet metal forming process, the final shape of parts depends on the springback quantity after forming, when the springback quantity exceeds allowed tolerance, the parts geometric accuracy will affect. The springback control is based on the accurate prediction of springback quantity, however the springback rule difference of stamping parts with different material and shape is large. Finite element numerical simulation technique provides a good tool for the prediction and control of springback. By numerical simulation, springback deformation of automotive stamping parts after forming is accurately predicted, and springback control method is studied base on this, in order to improve forming precision, which has important significance in reduce the cost of automotive stamping parts, ensure the vehicle assembly quality, shorten the new product development cycle [1]. In 2006, Dongjuan Zhang [2] is proposed nonlinear anisotropic hardening constitutive model considering Bauschinger effect, and analyzes the influence of different yield criterion and strengthening mode on springback quantity of sheet metal, the results show that the prediction results for springback of nonlinear anisotropic hardening constitutive model approach the experiment. In 2007, Du Song [3] adopted kinematic hardening constitutive model and isotropic hardening model and finite element analyze sheet metal stretch bending, analyze the influence of Bauschinger effect on stretch bending springback. In 2011, Kangkang $\mathrm{Hu}$ etal [4] used Yoshida-Uemori kinematic hardening material model and isotropic hardening material model respectively to simulation analysis and springback prediction of automobile high strength steel structure stamp forming, study the influence of different material hardening model on springback prediction accuracy, and compare the simulation results with the experimental data. 2012, Bing-tao Tang etal. [5] revised the original back stress calculation formula on the basis of nonlinear kinematic hardening theory of Lemaitre and Chaboche, put forward a kind of effective back stresses parameters which combine the isotropic hardening model of Chaboche with this revisional kinematic hardening model, and a new anisotropic hardening model was given. In 2012, Zhang $\mathrm{Lu}[6]$ determined nine parameters of Yoshida. Uemori kinematic hardening model through tensile compression test, compared springback prediction and test of different material model, verified the validity of springback prediction of Yoshida-Uemori model. Compared with traditional steel grade, the springback phenomenon of high strength steel is more obvious, the reasons are as follows: 1) the flow stress of high strength steel stamping parts is higher, yield and hardening appear after material deformation, which lead to larger elastic stress on stamping parts; 2) the springback mechanism of high-strength steel is different from that of ordinary steel grade. When the high-strength steel is loaded in reverse, it will have Bauschinger effect. After a certain quantity of uniaxial tension and compressive plastic deformation, and reverse loading after that, the material yield strength will be lower than the yield strength of continuous normal deformation, this phenomenon is called BAUSCHINGER effect. Bauschinger effect is a common phenomenon of metal materials, which reduces the yield strength of materials after pre-stretching and reverse loading after that, which leads to anisotropy of material properties [7]. In this paper, the effect of kinematic hardening model parameters, which are related with BAUSCHINGER effect, on springback of high strength steel stamping with considered is studied. Advanced kinematic hardening model available in AutoForm is applied in this study. This model describes the following three phenomena: early re-plastification; transient softening; work hardening stagnation. The unique formulation of the model makes it possible to describe the nonlinear stress-stain response right after the load reversal and to cover early re-yielding which is as important for springback prediction. To define the stress-strain relationship after the load reversal, experimental tension-compression curves can be imported and the required material parameters will be adjusted automatically. Multiple compression curves can be fitted to determine a single set of kinematic hardening parameters [8]. 


\section{DESIGN Of TEST}

There are several parameters in kinematic hardening model that are related with Bauschinger effect, which are studied in this paper:

Transient Softening Rate K: Transient softening mainly cause the reduction of hardening stress as compared to isotropic hardening. The value may range from 0 to 0.1 .

Stagnation Ratio $\xi$ : Also stagnation ratio causes a reduction in hardening stress. This effects looks like a hardening delay for certain strain amount. The value may range from 0 to 1 .

Young's Reduction Factor Y: Parameter to describe the reduction of the initial Young's modulus $E$ as a function of the plastic strain. Values may range from 0 to 0.5 .

Young's Reduction Rate $\chi$ : Parameter to describe the reduction the initial Young's modulus $\mathrm{E}$ as a function of the plastic strain. It is used in case of more than more compression curve is available. The value may range from 0 to 100 . If one compression curve was used for fitting, it is recommended to set a default of 40 .

Reversal Strain $\varepsilon_{\text {Rev }}$ : Reversal strain is used for visualization of compression curve in the $2 \mathrm{D}$ plot of the hardening curve.

The part in stamping process is $\mathrm{S}$ shape beam, thickness $0.9 \mathrm{~mm}$, friction coefficient 0.11 , The material used in the test is DP590 produced by Shougang Group, the material property is listed in Figure I. Stamping holder force is $300 \mathrm{kN}$, velocity $240 \mathrm{~mm} / \mathrm{s}$.

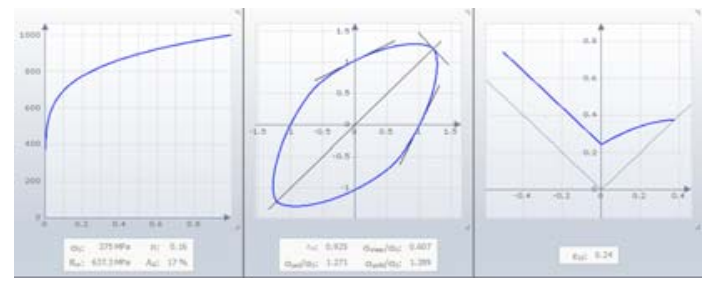

FIGURE I. MATERIAL PROPERTY OF HC340590DP

\section{FinITE ELEMENT MODEL}

The $\mathrm{S}$ shape beam stamping simulation model built in Autoform is shown in Figure 2.

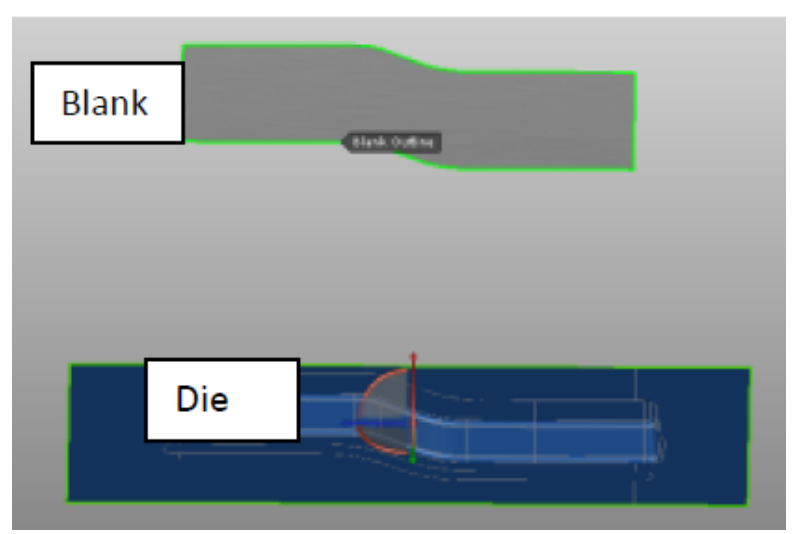

FIGURE II. STAMPING SIMULATION MODEL
The simulation result after stamping forming is shown below:

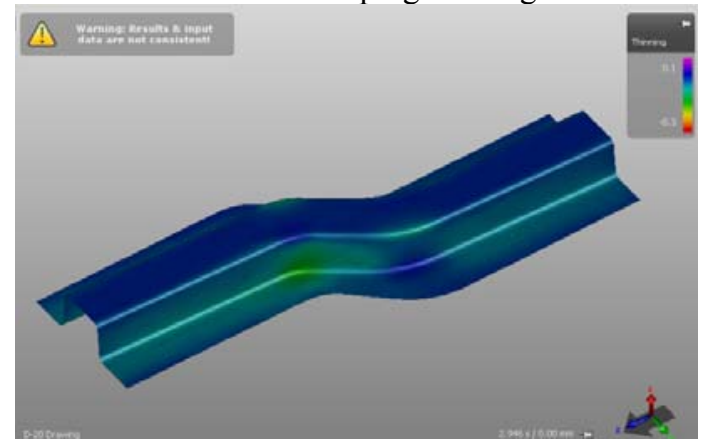

FIGURE III. SIMULATION RESULT AFTER STAMPING FORMING

The original value of parameters of kinematic hardening model of HC340590DP are Transient Softening Rate $\mathrm{k}=0.014$; Stagnation Ratio $\S=0.9$; Young's Reduction Factor $\mathrm{V}=0.13$; Young's Reduction Rate $\chi=40$. The curve shape in the kinematic model is changed with the change of these parameters. Set the variation range of $\kappa, \xi, \gamma, \chi$ are $0.0224-0.0084,0.27-1,0.208-0.078,24-64$. After stamping simulation of the part, the effect of these parameters on the springback quantity after stamping is obtained.

\section{RESULTS AND DISSCUSION}

It is observed from Figure 3 that, the influence of Young's Reduction Factor $\mathrm{Y}$ and Young's Reduction Rate $\chi$ on springback is not obvious. With the increasing of transient softening rate $\kappa$, the maximum springback increases. The increasing of Stagnation Ratio $\zeta$ reduce the springback.

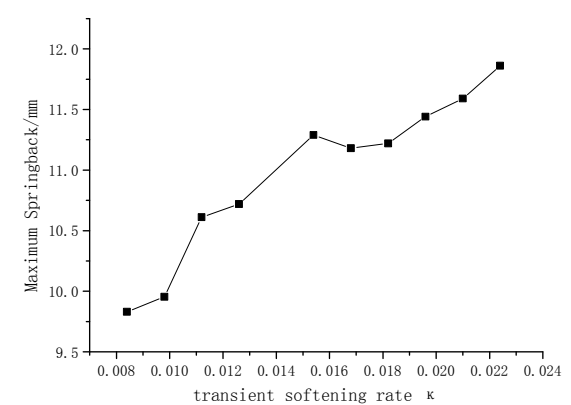

FIGURE IV. (a)

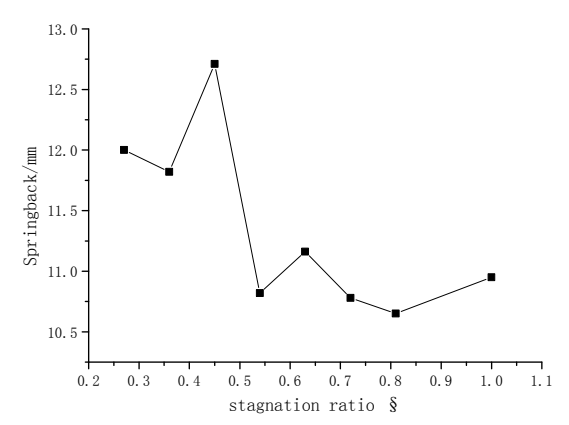

FIGURE IV. (b) 


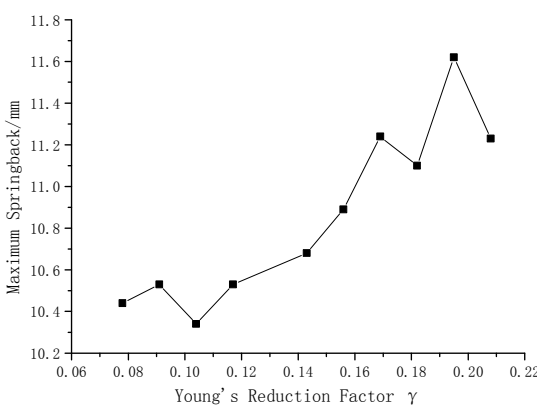

FIGURE IV. (c)

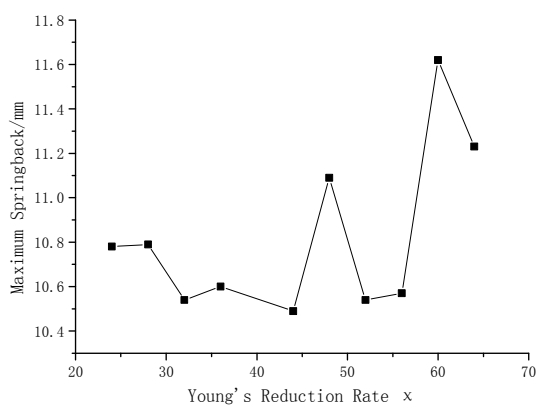

FIGURE IV. (d)

FIGURE IV. INFLUENCE OF PARAMETERS IN KINEMATIC HARDENING MODEL ON SPRINGBACK.

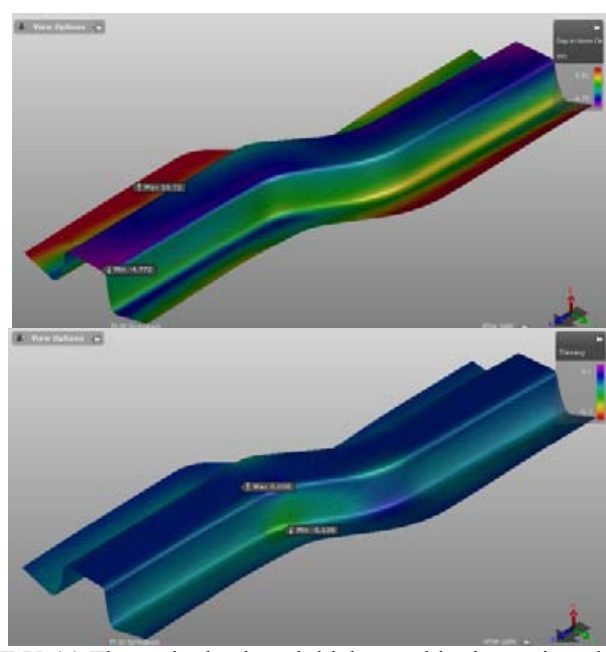

FIGURE V. (a) The springback and thickness thinning ratio value of the s-shaped u-channel part when $\mathrm{k}$ is 0.0126

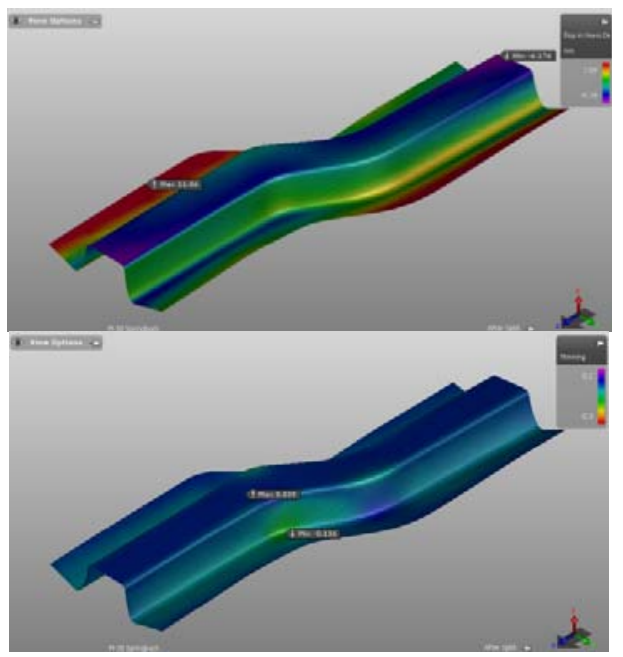

FIGURE V. (b) The springback and thickness thinning ratio value of the S-shaped U-channel part when $\mathrm{k}$ is 0.0224 .

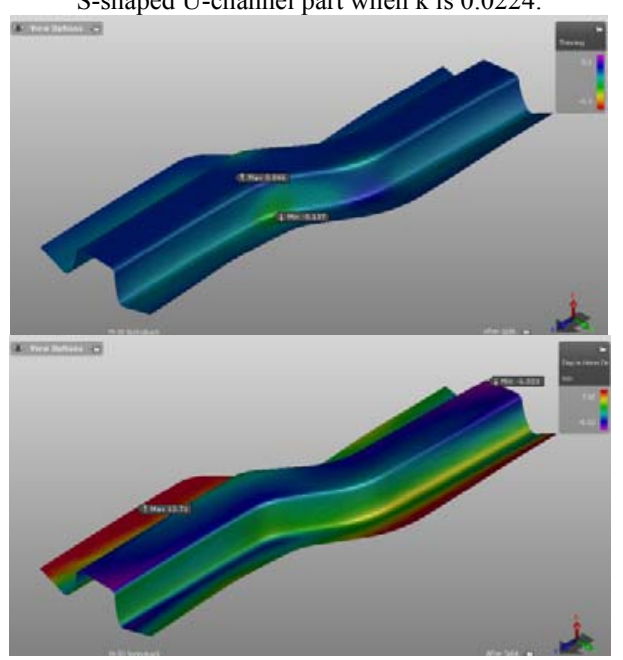

FIGURE V. (c) The springback and thickness thinning ratio value of the S-shaped U-channel part when $\zeta$ is 0.45 .

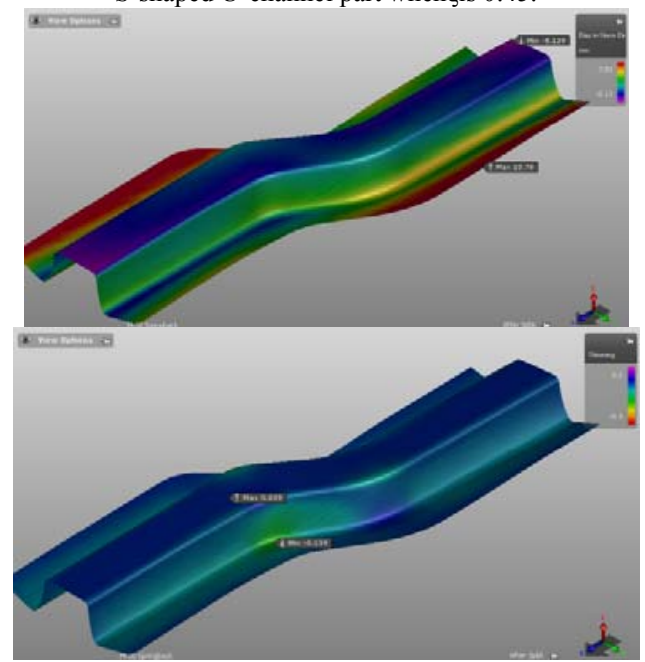

FIGURE V. (d) The springback and thickness thinning ratio value of the S-shaped U-channel part when $\zeta$ is 0.72 .

FIGURE V. INFLUENCE OF TRANSIENT SOFTENING RATE K AND STAGNATION RATIO Z ON SPRINGBACK AND THICKNESS THINNING RATIO. 
The result value obtained from Figure 5 is that, (a) $\mathrm{k}=0.0126$, maximum springback $10.72 \mathrm{~mm}$, minimum springback $-4.772 \mathrm{~mm}$; maximum thickness thinning ratio 0.038 ; minimum thickness thinning ratio -0.138 . (b) $\mathrm{k}=0.0224$, maximum springback $11.86 \mathrm{~mm}$, minimum springback $-6.176 \mathrm{~mm}$; maximum thickness thinning ratio 0.039 , minimum thickness thinning ratio -0.136 . (c) $\zeta=0.45$, maximum springback $12.71 \mathrm{~mm}$, minimum springback $-6.023 \mathrm{~mm}$; maximum thickness thinning ratio 0.046 , minimum thickness thinning ratio -0.137 . (d) $\zeta=0.72$, maximum springback $10.78 \mathrm{~mm}$, minimum springback $-5.129 \mathrm{~mm}$; maximum thickness thinning ratio 0.039 , minimum thickness thinning ratio -0.139 .

Compare the simulation result of transient softening rate $\kappa=0,0126$ and 0.0224 , the difference between the maximum springback is $1.14 \mathrm{~mm}$; compare the simulation result of Stagnation Ratio $\zeta=0.45$ and 0.72 , the dfference between the maximum springback is $1.93 \mathrm{~mm}$. The influence of these parameters on the thickness thinning ratio is not obvious.

\section{CONCLUSION}

In this paper, simulation software Autoform is applied in the stamping simulation of HC340590DP S shape beam, effect of parameters in the material kinematic hardening model, which are related with Bauschinger effect, on springback and thickness thinning ratio after stamping is studied. Set a certain range of value of transient softening rate $\kappa$, Stagnation Ratio $\zeta$, Young's Reduction Factor $Y$ and Young's Reduction Rate $\chi$, after stamping simulation, the relationship between parameters and springback, thickness thinning ratio is obtained. The following conclusions are obtained: the influence of Young's Reduction Factor $\mathrm{Y}$ and Young's Reduction Rate $\chi$ on springback is not obvious; With the increasing of transient softening rate $\kappa$, the maximum springback increases. The increasing of Stagnation Ratio $\zeta$ reduce the springback. The influence of these parameters on the thickness thinning ratio is not obvious.

\section{REFERENCES}

[1] Zhongqin Lin. forming simulation of auto-body panels [M]. Beijing: China Machine Press, 2004.

[2] Dongjuan Zhang. The Springback Theory and Finite Element Simulation Research of Panel Stamping Forming: [PHD Thesis of Shanghai Jiao Tong University]. Shanghai: Shanghai Jiao Tong University. 2006

[3] Song Du. influence of bauschinger effect on springback in sheet metal stretch bending, 2007, 33(2): 206-209.

[4] Kangkang Hu, PENG Xiong-qi, CHEN Jun etal. Springback prediction of automobile body panel based on Yoshida-Uemori material model. Materials Science and Technology, 2011, 19(6): 43. 47.

[5] Tang Bingtao, Lu Xiaoyang. Study in the Mixed Nonlinear Hardening (M-NH) Model for Multiaxial. Mechanical Science and Technology for Aerospace Engineering, 2012, 3 1(2): 306-316.

[6] Lu Zhang. Effects of Material Models on Springback Predictions and Compensations in Stamping Advanced High-Strength Steels: [Master Thesis of Shanghai Jiao Tong University]. Shanghai: Shanghai Jiao Tong University. 2012.

[7] Wang Wenping, Diao Keshan etal. Review on Yielding and Hardening Behavior of Sheet Metal[J]. Journal of Mechanical Engineering, 2013, Vol.49 No.24:9.

[8] AutoForm R7 Software Manual. 